\title{
International Journal of Finance and Accounting
}

(IJFA)

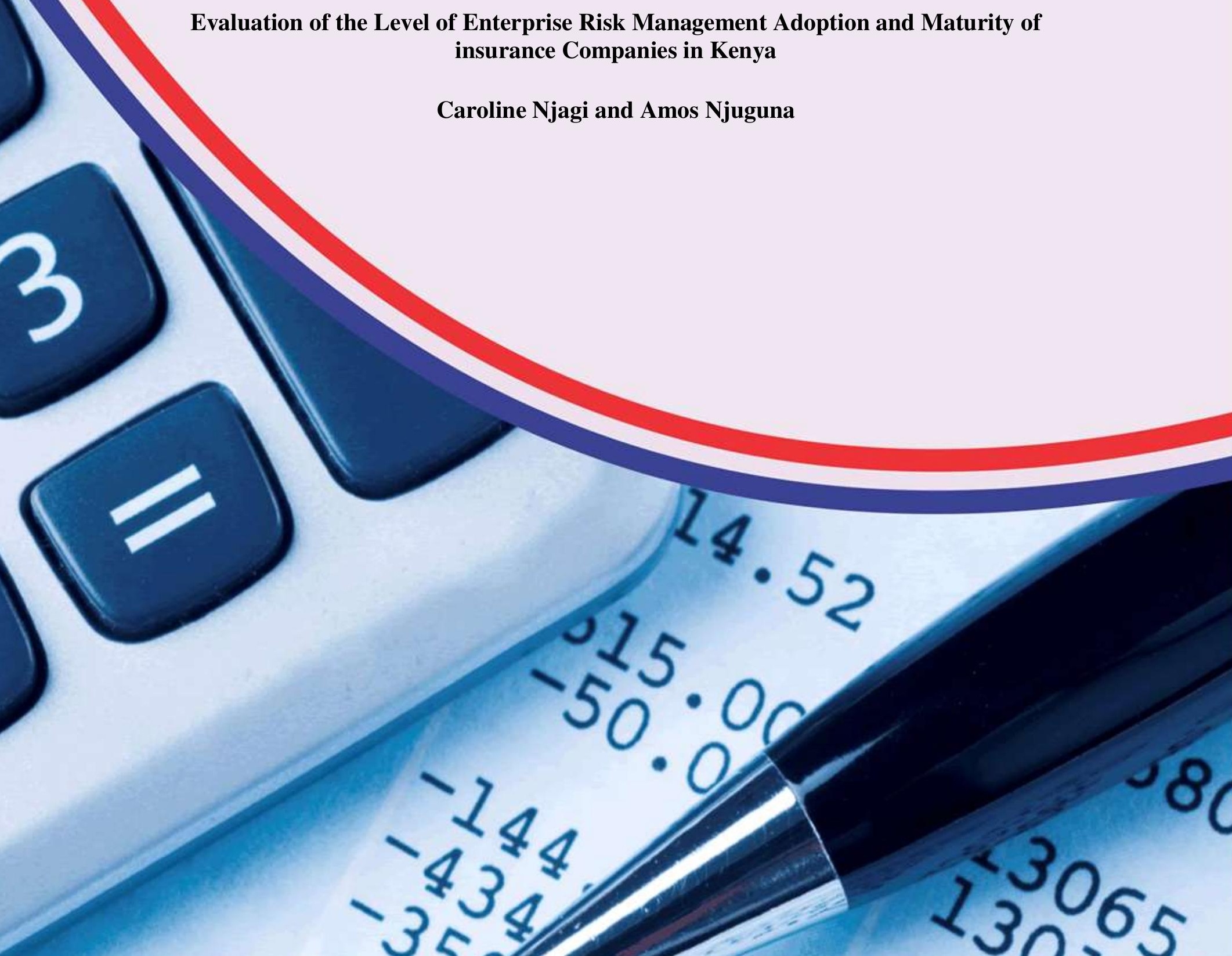




\title{
Evaluation of the Level of Enterprise Risk Management Adoption and Maturity of Insurance Companies in Kenya
}

\author{
${ }^{1}$ Caroline Njagi \\ Post Graduate Student :United States International University Africa \\ *Corresponding Author's Email: caroline.njagi@gmail.com \\ ${ }^{2}$ Dr. Amos Njuguna, \\ Lecturer: United States International University Africa
}

\begin{abstract}
Purpose: The purpose of this study was to evaluate the extent to which insurance companies in Kenya have adopted ERM process, and then to assess the maturity, challenges and strategies in the implementation of this process.

Materials and methods: The research design adopted for the study is descriptive research. The researcher conducted a survey on the 49 insurance companies of Kenya to encapsulate the factors that are relevant in articulating the extent of adoption of ERM and the level of maturity. A sample of 196 respondents was selected from a population of 245 respondents. The study used quantitative and qualitative methods of data analysis. Statistical Package for Social Sciences (SPSS) version 20 program was used for analysis. The results were presented using tables and pie charts. Similarly, qualitative data was summarized and categorized according to common themes and presentedin continuous prose form.

Results: The study concluded that organizational related challenges hindered implementation of ERM programs. Results revealed that inadequate application of the risk management framework, ambiguity in roles and responsibilities in risk management, complexities in risk measurement, lack of embodiment of ERM in organizational culture, difficulty in risk quantification, linking risk information to strategic decision making, ensuring that all decisions remain within the organization's risk tolerance, proactively identifying current and emerging risks, cost and budgetary constraints, misalignment of the risk and business operating models, risk management not seen as a priority by top management and inadequate information to make risk-based decisions hindered implementation of ERM frameworks among insurance firms in Kenya. The findings imply that organization related challenges have a significant effect on ERM implementation.

Recommendations: The study recommends that there should be better organizational strategies to help improve implementation of ERM programs. It was found that building a strong risk
\end{abstract}


culture, engaging consultants, building a dedicated ERM function, committed board of directors and top management, developing risk appetite statement, appointment of a Chief Risk Officer (CRO) and availing ERM budgets improved the implementation of ERM programs.

Key words: enterprise risk management, adoption, maturity

\subsection{Introduction}

\subsection{Background of the Study}

Enterprise Risk Management (ERM) has been a developing area of practice for actuaries for over 10 years. Advisory Committee on Enterprise Risk Management produced a report that recommends areas of research and education that are needed by actuaries entering this emerging field (D'Arcy \& Brogan, 2001). The SOA, (2002) formed a Risk Management Task Force that wrote guides to Economic Capital and Enterprise Risk Management practice as well as initiating several research projects. The task force evolved into a new Risk Management Section of the Society of Actuaries (SOA, 2004) and became the first and largest joint activity in 2005 when it became the Joint Risk Management Section cosponsored by the SOA and the Canadian Institute of Actuaries (CIA). The Joint Risk Management Section has been tightly linked with an annual ERM Symposium event that started as a joint activity of the SOA and the Professional Risk Managers' International Association (PRMIA).

Effective risk management can bring far reaching benefits to all organizations, whether large or small, public or private sector (Ranong \& Phuenngam, 2009). A recent study by Hoyt and Liebenberg (2011) provides evidence of the value relevance for insurance companies. They estimated the effect of ERM using Tobin's Q and find a positive relationship between the use of ERM and firm value. The ERM premium of roughly 20\%(percent) is both statistically and economically significant. Some research papers present evidence to indicate that ERM improves firm performance (McShane, Nair \& Rustambekov, 2011). ERM is value adding to firms by enabling objective capital allocation as a result of risk-return tradeoff assessments, as well as by mitigating financial risks and exploiting business risks which in turn leads to gaining and maintaining competitive advantage (Hoyt \& Liebenberg, 2011). US-based studies of the financial sector Hoyt and Liebenberg (2011) found that US insurance firms adopting ERM were likely to lower their marginal cost of adopting risk.

The trend towards the adoption of ERM programs is attributed to a combination of external and internal pressure. Manab, Kassim and Hussin (2010) argued that the reasons for an organization to adopt between the formal or informal RM approach is due to the RM adoption drivers such as corporate governance, compliance to regulations, technology advancements and competitive advantage. Based on the RM adoption drivers, the implementation of RM practices is dependent upon the firm and industrial factors, internal factors, and external factors (Ismail, Rose, Uli \& Abdullah, 2012)

\subsection{Statement of the Problem}

According to COSO ERM Frameworks study, ERM is already an accepted approach to deal with business wide risks; however the stage of most ERM systems is still very immature. Although the idea of ERM has gained widespread acceptance as a key component of effective governance, organizations vary in the extent to which they have adopted it. According to Paape and Spekle 
(2012), some organizations have invested in sophisticated ERM systems, whereas others rely on rather ad hoc responses to risks as they become manifest.A research conducted by Ernst \& Young (2012) revealed that organizations with greater risk management maturity outperform their peers financially. Only a few organizations have implemented a systematic, robust and repeatable process of ERM. A large number of organizations is still not satisfied with their process of risk assessment and need further guidance in implementing ERM (Beasley, Branson \& Hancock, 2010).

Mature risk management companies are companies that are very capable of identifying, measuring and monitoring risks across their organizations; process these risks dynamically and can easily adapt to change. These companies also align their risk management process with their strategic objectives efficiently and effectively (AON, 2013). Risk maturities models have been developed to measure the level of ERM maturity.Zhao, Hwang and Low (2013) developed an enterprise risk management maturity model (ERMMM) consisting of 16 important ERM maturity criteria and presented 66 applicable best practices under these criteria and this can be applied in companies to measure maturity and identify areas of improvement.

ERM studies such as Wanjohi and Ombui (2013); Yegon, Mouni and Wanjau (2014), Waweru and Kisaka (2012) have been conducted in the financial market of Kenya and mainly cover banking institutions and listed companies and only a few cover the insurance sector. Furthermore, the maturity of ERM has not been tested in the studies that have measured the value of ERM implementation. It would follow then that management would be interested to know the level of maturity of their risk management programs and what strategies can be put in place to improve the ERM practices so that the company can derive value from it. Therefore, this study addressed this knowledge and management gap as a direct relationship exists between ERM maturity and value derived from the program.

\subsection{Research objective}

\subsection{To determine the level of maturity of the ERM programs}

\subsection{Scope of the Study}

The study targeted all insurance and reinsurance companies in Kenya. The study entailed a questionnaire survey with the requisite criteria to measure the level of ERM maturity. Data collection phase was conducted in the month of May 2015.

There was a possibility of not receiving responses from all the respondents sampled. To mitigate this, follow up calls was made and interviews arranged to increase our response rate. Further, to mitigate against possibility of question misinterpretation, the questionnaire was tested with a few risk managers who assessed areas that were not clear. Alternatively inconsistencies were followed up with follow up interviews.

\subsection{LITERATURE REVIEW}

\subsection{Enterprise Risk Managements Frameworks}

This section provides literature review analysis of enterprise risk management basing arguments on ERM Frameworks, Risk Management Maturity levels, strategies and challenges in the implementation of ERM. Enterprise Risk Management is a globally accepted and growing field. 
As a result, a number of risk frameworks and statements have been published by professional organizations around the world. Some of the publications urge businesses to use these frameworks. The ERM Process is the time-tested foundation of risk management methodology, pioneered by the risk management discipline and detailed in the Associate in Risk Management (ARM) designation program (Framework,2004). Some of the ERM frameworks include; The Combined Code and Turnbull Guidance. The Code states that the role of the board is to provide a framework of effective control so that risk is assessed and managed. The board is also required to review the effectiveness of controls, including all controls over financial, operational, and compliance areas as well as risk management systems (McCrae \& Balthazor, 2000). This framework was published in 2002 to promote corporate governance and has 5 sections including Board and directors, Risk management, internal audit, integrated sustainability reporting and accounting and auditing. According to this framework, the board is responsible for the risk management process and its effectiveness.

\subsection{ISO 31000: 2009, Risk Management - Principles and Guidelines}

ISO 31000: 2009, Risk Management framework is also among the common risk management frameworks used. While all organizations manage risk to some degree, this International Standard establishes a number of principles that need to be satisfied to make risk management effective. This International Standard recommends that organizations develop, implement and continuously improve a framework whose purpose is to integrate the process for managing risk into the organization's overall governance, strategy and planning, management, reporting processes, policies, values and culture (ISO, 2009).

Zhao, Hwang, \& Low (2013)developed an enterprise risk management maturity model (ERMMM) consisting of 16 important ERM maturity dimensions or criteria and presented 66 applicable best practices or sub-dimensions under these criteria. The ERM maturity criterion scores can provide the management staff with a clear understanding of their strengths and weaknesses of the ERM implementation.

\subsection{Standard and Poor's, (IMA, 2011)}

Standard and Poor's, (IMA, 2011) is another ERM framework that has already started to incorporate the company's ERM practice into the Standard and Poor rating of the company. It currently applies this rating to both financial institutions and insurers. Its framework for evaluating ERM at banks includes a review of ERM policies, ERM infrastructure and ERM methodology. ERM policies should address risk culture, appetite and strategy, control and monitoring, disclosure and awareness.ERM methodology refers to capital allocation, model vetting and valuation methods. ERM infrastructure covers risk technology, operations and risk training. The framework for evaluating insurers includes an assessment of risk management culture, risk controls, emerging risk management, risk and capital models and strategic risk management. Standard and poor rates for the insurer can be rated as weak, adequate, strong or excellent. An adequate rating would mean an insurer has fully functioning risk control systems.

\subsection{The King II Report on corporate governance for South Africa(2002)}

The King II Report on corporate governance for South Africa (King II Report, 2002) was published to promote corporate governance. The report consists of five sections including; Board of directors, risk management, internal audit, integrated sustainability reporting and accounting 
and auditing. It also includes an appendix on risk management and internal controls. According to the report, the board is responsible for the risk management process and its effectiveness. It sets risk strategy policies, assessing the risk process assessing the risk exposures, such as physical and operational risks, human resource risks, technology risks, business continuity and disaster recovery, credit, market risks and compliance risks, reviewing the risk management process and significant risks facing the company and be responsible for risk management disclosures.

\subsection{RESEARCH METHODOLOGY}

The research design adopted for the study is descriptive research.According to the Insurance Regulatory Authority of Kenya report of 2014, there are 49 licensed insurance companies in Kenya. The target population of this study comprised of chief risk officers, heads /directors of risk, chief internal auditors and compliance officers from the sample 49 insurance companies. Probability sampling was used in sample selection so as to avoid selection bias. Particularly, simple random sampling was used to pick the sample size. The data was coded and input by the use of a data capturing software and exported to statistical package SPSS. Data inputs were cleaned by checking for consistency and validity. It underwent a data preparation process where the data was coded, edited and cleaned.

The data was quantitative in nature therefore descriptive statistics, frequencies, percentages and rank was used to analyze the data. The overall RMM score for a particular organization was obtained by aggregating scores of individual dimensions by using a simple averaging method. An individual dimension score, in turn, was computed by using the similar procedure of corresponding sub dimensions. The score of a sub dimension was calculated by using a factor score method. A factor score method suggests that the sub dimension score is calculated by summing up the weighted value of item responses. The weighting factor is derived from the item's factor loading of the factor analysis. The mean scores were then ranked to see which of the ERM maturity factors is the most prominent. Data analysis results will be presented in tables.

\subsection{RESULTS PRESENTATION AND DISCUSION}

\subsection{Data Analysis}

\subsection{Response Rate}

A total of 196 questionnaires were printed and distributed to the identified respondents. Table 1 showed the total number of questionnaires distributed where 155 were properly filled and returned. This represented a response rate of 79.1\%. According to Mugenda \& Mugenda (2003) and Kothari (2004) a response rate of 50\% is adequate for a descriptive study. Babbie (2004) also asserted that return rates of 50\% are acceptable to analyze and publish, $60 \%$ is good and $70 \%$ is very good. Based on these assertions from renowned scholars $79.1 \%$ response rate is adequate for the study.

Table 1 Response Rate

\begin{tabular}{llll}
\hline Category & Returned & Unreturned & Total \\
\hline Chief Risk Officers & $40(81.6 \%)$ & $9(19.4 \%)$ & $49(100 \%)$ \\
\hline
\end{tabular}




\begin{tabular}{llll}
\hline Heads /Directors Of Risk & $35(71.4 \%)$ & $14(28.6 \%)$ & $49(100 \%)$ \\
Chief Internal Auditors & $42(85.7 \%)$ & $7(14.3 \%)$ & $49(100 \%)$ \\
Compliance Officers & $38(77.6 \%)$ & $11(22.4 \%)$ & $49(100 \%)$ \\
Total & $\mathbf{1 5 5 ( 7 9 . 1 \% )}$ & $\mathbf{4 1 ( \mathbf { 2 0 . 9 \% } )}$ & $\mathbf{1 9 6}(\mathbf{1 0 0 \% )}$ \\
\hline
\end{tabular}

\subsection{Demographic characteristics}

This section contains results on socio-demographic characteristics of the respondents. These characteristics include; type of the company, size of the company, department of the respondent, position of the respondent and number of years the respondent had worked.

\subsubsection{Type of Business}

Majority (50\%) of the insurance firms analyzed specialized on General insurance. Twenty nine percent $(29 \%)$ of the insurance firms were specializing on Composite insurance while the remaining $21 \%$ were dealing with Life insurance.

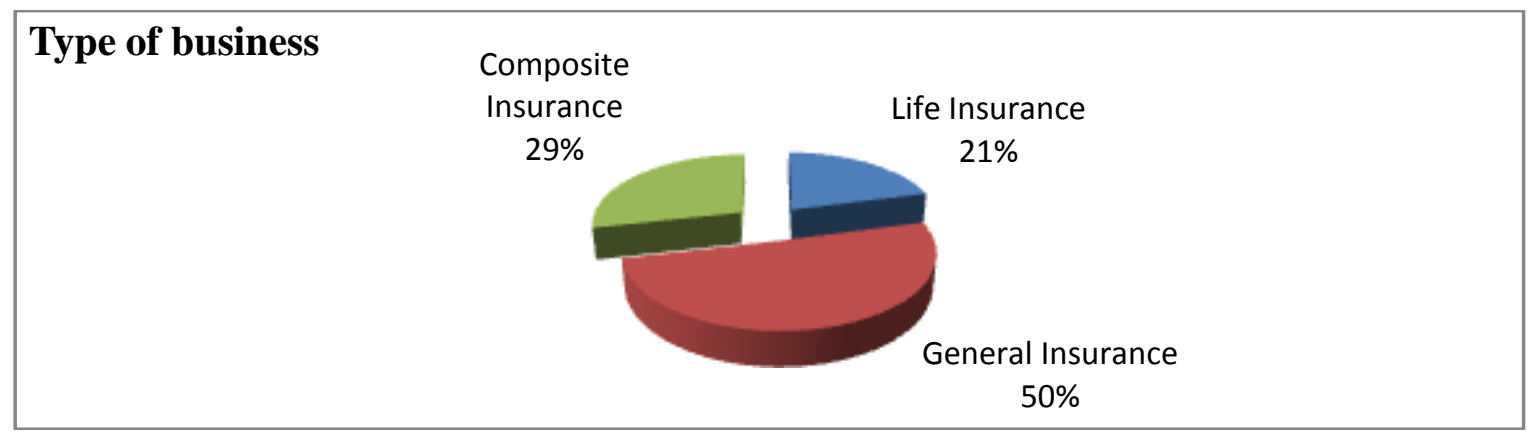

\section{Figure 1 Type of Business}

\subsubsection{Size of the Company}

Majority (39\%) of the Insurance companies were between size Ksh2Bn-Ksh4Bn by worth. Twenty nine percent (29\%) of the Insurance firms were in between Ksh5Bn-Ksh9Bn by size, twenty seven percent (27\%) had Ksh 10Bn and above with only 5\% of the insurance firms being Ksh1Bn and below by size.

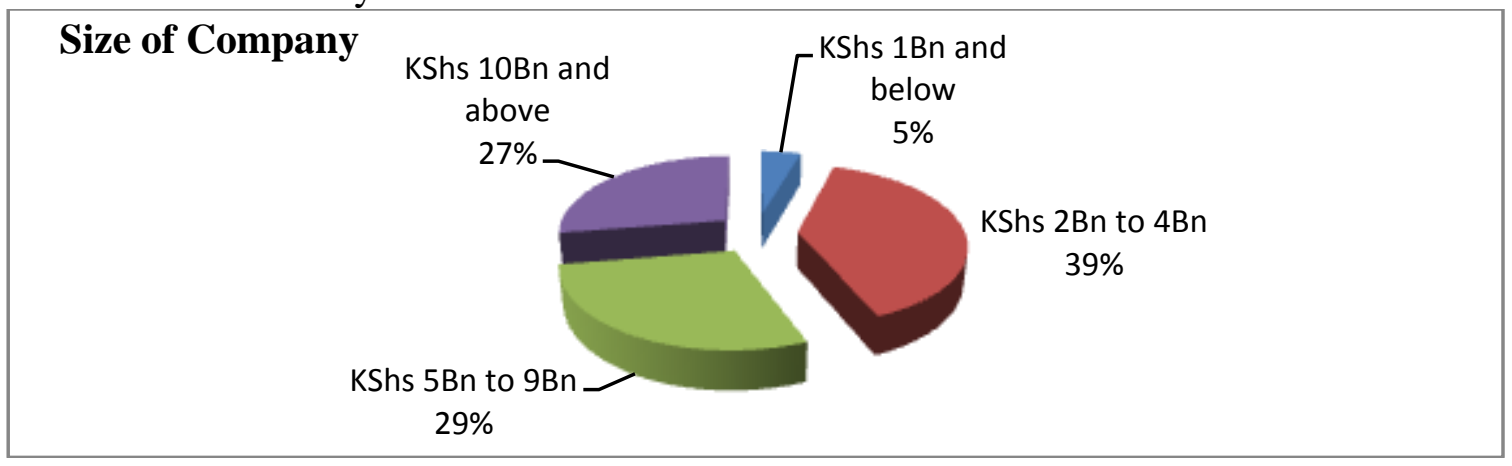




\section{Figure 2 Size of the Company}

\subsubsection{Department of the Respondent}

Respondents were asked to indicate the department they were working in.

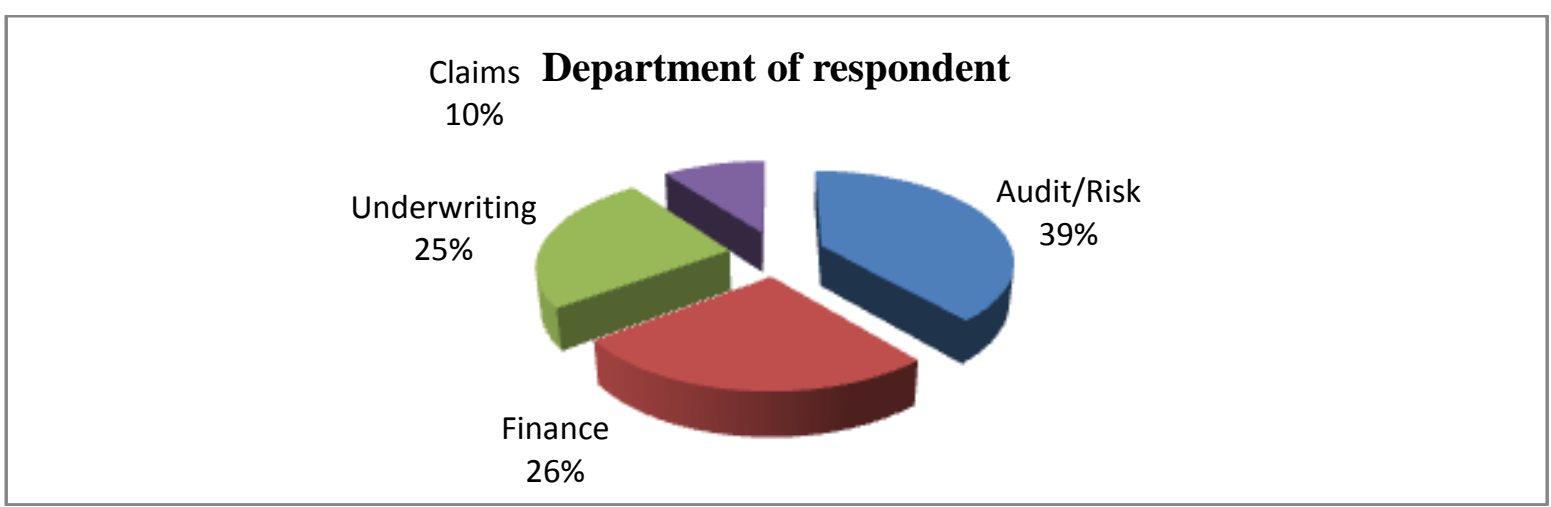

Figure 3 Department of the Respondent

Majority thirty nine percent (39\%) were in the Audit and Risk department, 26\% of the respondents were in the Finance department, 25\% in the Underwriting department with only 10\% in the Claims department.

\subsubsection{Position of the Respondent}

Respondents were asked to indicate their positions in their respective Insurance firms. Majority (33\%) were in the Mid-level Management, 32\% were in the Top Management with only 18\% and $17 \%$ in the Lower level Management and Operations respectively.

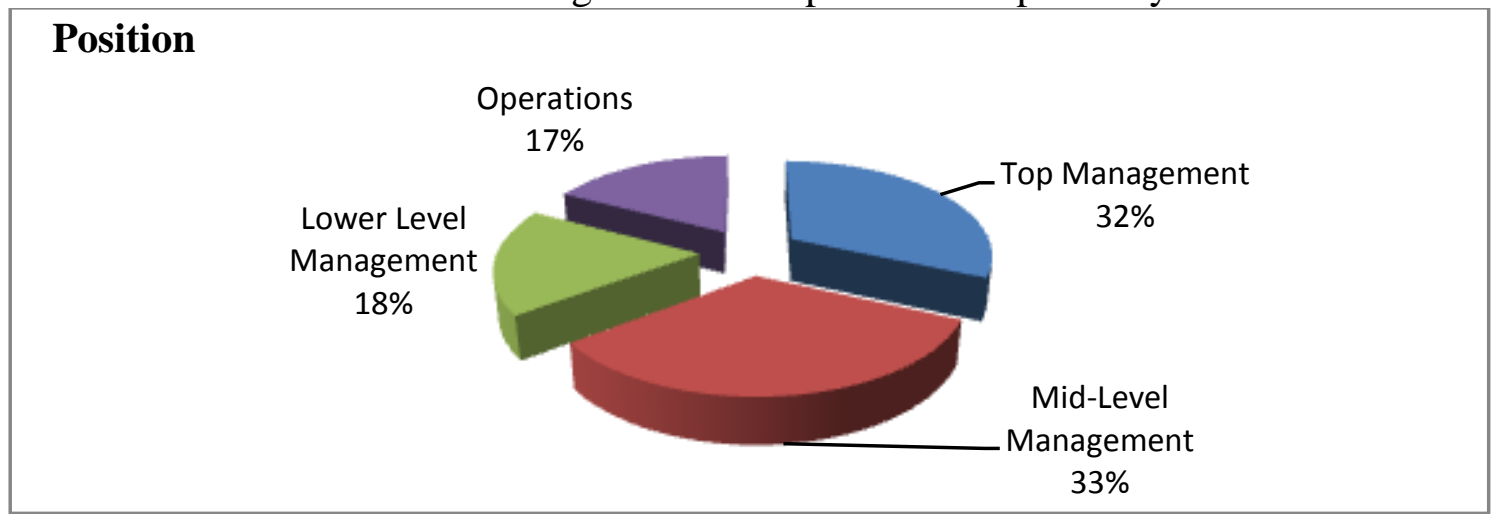

\section{Figure 4 Position of the Respondent}

\subsubsection{Number of Years Worked}

Further respondents were asked to indicate the number of years worked in their Insurance companies. Majority (34\%) had worked for a period of between 2-3years, 23\% had worked for $4-5 y e a r s$. Twenty two percent $(22 \%)$ had work experience in their companies of 6years and above while $21 \%$ had less than 1year work duration. 


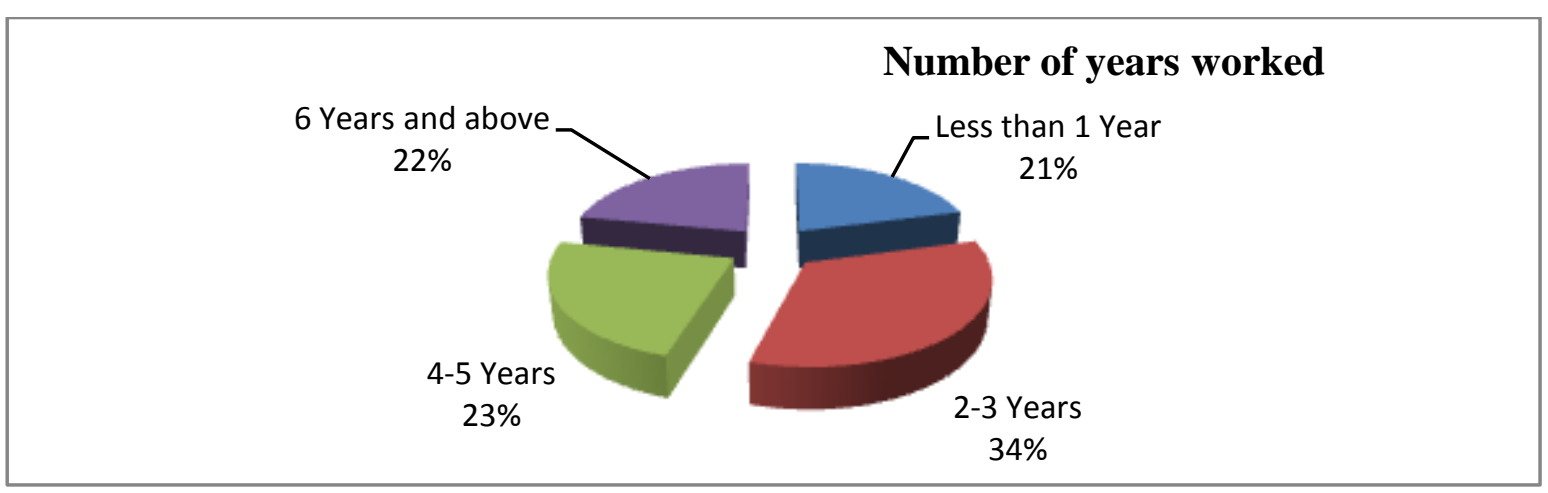

\section{Figure 5 Number of Years Worked}

\subsection{Level of maturity of ERM Programs}

Analysis of the level of maturity of the ERM Programs was done and presented as shown in the table 3. Most insurance firms were "Normalized" with 69.9\%. Insurance firms at "Novice" level had $12.2 \%$, "Natural" level at $11.2 \%$ and "Naïve" at $6.6 \%$.

Table 3 Level of maturity of ERM Programs

\begin{tabular}{|ll|}
\hline Level of maturity & Percent \\
\hline Naïve & 6.6 \\
Novice & 12.2 \\
Normalized & 69.9 \\
Natural & 11.2 \\
Total & 100 \\
\hline
\end{tabular}

\subsection{DISCUSSION, CONCLUSIONS AND RECOMMENDATIONS}

\subsection{Summary}

Results indicated that most insurance firms were at level "Normalized" with $69.9 \%$. Insurance firms at "Novice" level had 12.2\%, "Natural" level at $11.2 \%$ and "Naïve" at $6.6 \%$.

These findings agree with those of previous work done.Maturity models offer organizations a simple but effective method to measure the quality of their process. The concept of "maturity" applies to organizations at a state where the entity is in perfect condition in achieving its objectives. This elaborates that maturity models are used in numerous industries for the purposes of assessment and benchmarking as they allow organizations to measure their relative performance position on a pathway to maturity representing an optimal state. Risk maturity models are useful tools in understanding the degree of sophistication of a business risk management process, its reliability and effectiveness in identifying, assessing and managing risks and opportunities (Collier \& Esteban, 2007). 


\subsection{Conclusions}

It was possible to conclude that organizational related challenges hindered implementation of ERM frameworks. It was also possible to conclude that certain strategies could be used to mitigate the above mention organizational challenges and implement ERM frameworks. Results revealed that building a strong risk culture, appointment of a Chief Risk Officer (CRO), developing risk appetite, building a dedicated ERM function statement, availing ERM budgets, engaging consultants and board of directors and top management commitment would help in the implementation of the Enterprise Risk Management among insurance firms. The findings imply that strategies have a significant effect on ERM framework implementation. Results revealed that a good and effective ERM framework leads to better implementation of Enterprise Risk Management strategies reducing financial risks that banks face in Kenya. The findings imply that ERM frameworks have a significant effect on Enterprise Risk Management. Results indicated that most insurance firms were at level "Normalized" with 69.9\%. Insurance firms at "Novice" level had 12.2\%, "Natural" level at 11.2\% and "Naïve" at 6.6\%. This implies that level of maturity for most insurance firms is normalized.

\subsection{Recommendations}

The ISO 3100: 2009 should be adopted by the insurance firms as it is the most preferred while BS 31100: 2008 and OCEG "Red Book" 2.0: 2009 frameworks should be looked into to establish the reasons why they are least rated frameworks in the insurance industry. Insurance firms should be encouraged to adopt "Normalized" level of maturity as this level seem to be the most appropriate. Improvement of the existing policies coupled with development of new policies should be adopted so as to resolve the main challenges faced by insurance firms in implementing ERM. The insurance firms should employ the strategies that include building a strong risk culture, appointment of a Chief Risk Officer (CRO), developing risk appetite, building a dedicated ERM function statement, availing ERM budgets, engaging consultants and board of directors and top management commitment to curb the organizational related challenges that it faces when implementing Enterprise Risk Management.

\subsection{Recommendations for Further Studies}

The study recommends that further investigation be done on the benefits of Enterprise Risk Management among insurance firms in Kenya and adopting more and better strategies and ERM frameworks. The study also recommends that a similar study be undertaken in other state agencies and corporations to mitigate business risks. The study can also be replicated in nongovernmental organizations such as the United Nations.

\section{References}

Abdullah N. A., N. Zakuan, M. Khayon, M. S. Ariff, N. E. Bazin, \& M. Z. Saman(2012). Adoption of enterprise risk management practices in organization: A review. International Journal of Business \& Information Technology, 2(1), 1-9.

Accenture (2013).Global risk management study.Risk management for an era of greater uncertainty. Retrieved, (2015), from www.accenture.com/us-en/Pages/insight-globalrisk-management-study-2013-era-greater-uncertainty.aspx. 
Airmic, ALARM, and IRM (2010).A structured approach to Enterprise Risk Management and the requirements of ISO 31000.Retrieved April 06, 2015 from http://www.airmic.com/research/guides.

Akram Jalal-Karim. (2013). Leveraging enterprise risk management (ERM) for boosting competitive business advantages in Bahrain. World Journal of Entrepreneurship, Management andSustainable Development, 9(1) 65 - 75.

Aksel R, Robert Dahlstrom, Sven A. Haugland\& Arne Nygaard. 2009. Governance structures in the hotel industry. Journal of Business Research, 2009, 62(8), 841-847.

Althonayan, A., \& Sharif, A. M. (2010).Aligning business and technology strategy within the airline industry.International Journal of Business Information Systems, 6(1),

Andersen, E. and Jessen, S. (2003). Project maturity in organizations.International Journal of Project Management, 21, 457-461.

AON. 2013. Global risk management survey. Retrieved March 13, 2015, from http://www.aon.com/2013GlobalRisk/2013-Global-Risk-Management-Survey-updated05-01-2013.pdf.

Arena, M., Arnaboldi, M. and Azzone, G. (2010). The organizational dynamics of enterprise risk management, Accounting, Organizations and Society, 35(7), 659-675.

Arthur. (2013). Theory of economic growth (Vol. 7).Routledge.

Barbara Monda\& Marco Giorgino (2013).An enterprise risk management maturity model. Munich Personal RePEc Archive, MPRA Paper No. 45421, Politecnico di Milano Management, Economics and Industrial Engineering Department. Retrieved March 13, 2015, from http://mpra.ub.uni-muenchen.de/45421/.

Beasley, M. S., Branson, B. C., \& Hancock, B. V. (2010). Developing key risk indicators to strengthen enterprise risk management. ERM Initiative at North Carolina State University and the Committee of Sponsoring Organizations of the Treadway Commission, Raleigh, NC.

Beasley, M. S., Clune, R., \&Hermanson, D. R. (2005). Enterprise risk management: An empirical analysis of factors associated with the extent of implementation. Journal of Accounting and Public Policy, 24(6), 521-531.

Beasley, M. S., Pagach, D. \&Warr, R. (2008). The information conveyed in hiring announcements of senior executives overseeing enterprise-wide risk management processes. Journal of Accounting, Auditing, and Finance, 23(3), 311-332. 
Beasley, Mark Branson, Bruce Hancock \& Bonnie (2010a).Current State of Enterprise Risk Oversight and Market Perceptions of COSO's ERM Framework. In: COSO Thought Leadership in ERM -COSO's 2010 Report on ERM.

British Standard, B. S. 31100,(2008): Risk management-code of practice. London, UK: British Standards Institute.

Budi Hartono, Deo F.N., WijayaHilya \& M. Arini. (2014). An empirically verified project risk maturity model. International Journal of Managing Projects in Business, 7(2), 263 - 284.

Central Bank of Kenya (2006).Prudential Guidelines.

Central Bank of Kenya (2011).Risk Management Survey for the Banking Sector. Nairobi: Central Bank of Kenya Publication.

Chou, D. C., \& Chou, A. Y. (2009). Information systems outsourcing life cycle and risks analysis. Computer Standards \& Interfaces, 31(5), 1036-1043.

Ciorciari, M., \& Blattner, P. (2008). Enterprise risk management maturity-level assessment tool. In 2008 Enterprise risk management symposium, Chicago, IL (pp. 14-16).

Collier, J., \& Esteban, R. (2007).Corporate social responsibility and employee commitment.Business ethics: A European review, 16(1), 19-33.

Collier, P. M., Berry, A. J. \& Burke, G. T. (2007) Risk and management accounting: best practice guidelines for enterprise-wide internal control procedures. Oxford: CIMA/Elsevier.

COSO (2004).Enterprise risk management - integrated framework, executive summary. New York: AICPA. COSO - The Committee of Sponsoring Organizations of the Treadway Commission.

Cumming, R. B., Knutson, D., Cameron, B. A., \& Derrick, B. (2002).A comparative analysis of claims-based methods of health risk assessment for commercial populations.Final report to the Society of Actuaries

D’Arcy, S. P., \& Brogan, J. C. (2001). Enterprise risk management. Journal of Risk Management of Korea, 12(1), 207-228.

Dafikpaku, E. (2011). The strategic implications of enterprise risk management: a framework. In 2011 Enterprise Risk Management Symposium, Chicago, Illinois, USA. 
Daud W. N. W., Yazid, A. S., \& Hussin, M. R. (2010). The effect of chief risk officer (CRO) on enterprise risk management (ERM) practices: evidence from Malaysia, International Business \& Economics Research Journal, 9(11), 55-64.

Daud, W. N. W., Haron, H., \& Ibrahim, D. N. (2011). The role of quality board of directors in enterprise risk management (ERM) practices: evidence from binary logistic regression. International Journal of Business and Management, 6(12), 205-211.

Deloitte (2012).Enterprise risk management survey report of 2012, where do you stand. Nairobi. Deloitte Publication.

Duncan Galloway \& Rick Funston. (2000). The challenges of enterprise risk management. Balance Sheet, 8(6), 22 -25.

Ebrahim, S., Taylor, F., Ward, K., Beswick, A., Burke, M., \& Davey Smith, G. (2011). Multiple risk factor interventions for primary prevention of coronary heart disease.The Cochrane Library.

Eckles, D. L., Hoyt, R. E., \& Miller, S. M. (2011). The Impact of Enterprise Risk Management on the Marginal Cost of Reducing Risk: Evidence from the Insurance Industry.

EhsanElahi, (2013). Risk management: the next source of competitive advantage. Foresight, 15(2), $117-131$.

Elena Demidenko\& Patrick McNutt. (2010). The ethics of enterprise risk management as a key component of corporate governance. International Journal of Social Economics, 37(10), $802-815$.

Elkington, S. \&Smallman, C. (2002). Managing project risks: a case study from the utilities sector. Journal of Project Management, 20, 49-57.

Ernst \& Young (2012). Turning risk into results: How leading companies use risk management to fuel better performance. Retrieved March 25, 2015, from http://www.ey.com/Publication/vwLUAssets/Turning_risk_into_results/\$FILE/Turning\% 20risk\%20into\%20results_AU1082_1\%20Feb\%202012.pdf..

Fama, E. F., \& French, K. R. (2004). The capital asset pricing model: Theory and evidence. Journal of Economic Perspectives, 18, 25-46.

Framework, I. (2004). Enterprise risk management—integrated framework.

Fraser, I. \& Henry, W. (2007). Embedding risk management: structures and approaches. Managerial Auditing Journal, 22 (4), 392-409 
Fraser, J., \& Simkins, B. J. (2010).Enterprise Risk Management: Today's Leading Research and Best Practices for Tomorrow's Executives. John Wiley \& Sons.

Gates, S. \&Hexter, E.S. (2005).From risk management to risk strategy. New York: Conference Board.

Gatzert Nadine \& Martin Michael (2013).Department for insurance economics and risk management, WP, Friedrich-Alexander-University (FAU) of Erlangen-Nürnberg.

Golshan, N. M., \&Rasid, S. A. (2012). Determinants of enterprise risk management adoption: an empirical analysis of Malaysian public listed firms. International Journal of Social and Human Sciences, 6, 119-126.

Gordon, L.A., Loeb, M.P. \& Tseng, C. (2009). Enterprise risk management and firm performance: a contingency perspective. Journal of Accounting and Public Policy, 28, 301-327.

Govindarajan, D. (2011). Corporate risk appetite: Ensuring board and senior management accountability for risk. ICMA Centre, Henley Business School, University of Reading.

Gruber, M. J., \& Ross, S. A. (1978). The current status of the capital asset pricing model (CAPM).The Journal of Finance, 33(3), 885-901.

Guidelines on Risk Management and Internal Controls, February (2013), Insurance Regulatory Authority (Kenya)

Hoyt, R. E. \& Liebenberg, A. P. (201).The value of enterprise risk management.Journal of Risk and Insurance, 78 (4), 795-822.

IIF (2009).Risk Culture. Reform in the financial Services Industry: Strengthening Practices for a More Stable System.

Ismail, A. I., Rose, R. C., Uli, J., \& Abdullah, H. (2012).The relationship between organizational resources, capabilities, systems and competitive advantage.Asian Academy of Management Journal, 17(1), 151-173.

ISO 31000 (2009).Risk management - Principles and guidelines.International Organization for Standardization.

Jones, L., Bellis, M. A., Wood, S., Hughes, K., McCoy, E., Eckley, L., ...\& Officer, A. (2012). Prevalence and risk of violence against children with disabilities: a systematic review and meta-analysis of observational studies. The Lancet, 380(9845), 899-907. 
KanhaiCosmas. (2014). Factors influencing the adoption of enterprise risk management (ERM) practices by banks in Zimbabwe. International Journal of Business and Commerce, 3(6): 2225-2436.

Kerstin D., Simone O., \& Nicole Z. (2014). Challenges in implementing enterprise risk management. ACRN Journal of Finance and Risk Perspectives, 3(3), 1 - 14.

Kleffner, A. E., Lee, R. B. \&McGannon, B. (2003). The effect of corporate governance on the use of enterprise risk management: evidence from Canada. Risk Management and Insurance Review. 6, 53-73.

Kothari C. R., Research Methodology, Methods and Techniques, (Second Revised Edition), Copyright (C) 2004, 1990, 1985, New Age International (P) Ltd., Publishers

Lehner, O., Leitner-Hanetseder, S., Eken, M. H., Selimler, H., Kale, S., Ulusoy, V., ...\&Risik, E. A. ACRN JOURNAL OF FINANCE AND RISK PERSPECTIVES.

Little, A.D. (2013), Project risk management - an executive concern, Retrieved March 17, 2015, from www.adlittle.com.

Little, E. A., \&Eccles, M. P. (2010).A systematic review of the effectiveness of interventions to improve post-fracture investigation and management of patients at risk of osteoporosis. Implement Sci, 5(1), 80.

Schoech, D., Fitch, D., Macfadden, R., \&Schkade, L. L. (2002). From data to intelligence: Introducing the intelligent organization. Administration in Social Work, 26(1), 1-21.

Shenkir, W. G. \& Walker, P. L. (2011).Enterprise Risk Management: Frameworks, Elements and Integration. Montvale, NJ: Institute of Management Accountant (IMA).

The Republic of Kenya (2012). Kenya Gazette No. 3362 on guidelines on corporate governance practices by public listed companies in Kenya. Government Printer.

USBS (1998).Survey Design and Statistical Methodology Metadata.United States Bureau of the Census, Software and Standards Management Branch, Systems Support Division.Washington D.C. Section 3.3.23, pp 32.

Wanjohi James N., \& Ombui Kepha. (2013). Effects of risk management practices on the performance of insurance firms in Kenya: A case of AIG Insurance Company Ltd. International Journal of Science and Research (IJSR), 2(9) India Online ISSN: 2319-7064.

Waweru and Kisaka (2012).The Effect of Enterprise Risk Management implementation on the value of companies listed in the NSE. AAA 2012 Management Accounting Paper, available at http://ssrn.com/abstarct $=1907248$. 
Weill, P., \& Olson, M. H. (1989).An assessment of the contingency theory of management information systems.Journal of management information systems, 59-85.

Woods, M. (2009). A contingency perspective on the risk management control system within Birmingham City Council. Management Accounting Research, 20, 69-81.

Yamane, Taro. (1967). Statistics: An Introductory Analysis, 2nd Ed., New York: Harper and Row

Yegon C. Kibet, Mouni J. Gekara \& Wanjau Kenneth. (2014). Effects of firm size on enterprise risk management of listed firms in Kenya. IOSR Journal of Business and Management. 16(5), 86-95.

Zhao, X., Hwang, B. G., \& Low, S. P. (2013).Developing fuzzy enterprise risk management maturity model for construction firms.Journal of Construction Engineering and Management, 139(9), 1179-1189.

Zurich \& HBRAS (2012). Risk Management in a time of Global Uncertainty. Retrieved April 06, 2015 from https://www.zurich.com/fr-fr/media/news-releases/2012/2012-0117-01. 